\title{
Reinstatement of retrieval cues, intertrial interval, and resistance to extinction
}

\author{
JARED B. JOBE, MARY Z. MAYS, and ROGER L. MELLGREN \\ University of Oklahoma, Norman, Oklahoma 73019
}

It has been previously demonstrated that the failure to provide adequate retrieval cues reliably attenuates the resistance to extinction of a partially reinforced response with a long intertrial interval. The present experiment represented an attempt to determine whether the attenuating effect of nonreinstatement on resistance to extinction was less pronounced at shorter intertrial intervals. Reinstatement conditions were combined factorially with three intertrial intervals $(15 \mathrm{sec}, 15 \mathrm{~min}$, and $30 \mathrm{~min}$ ). Reinstatement resulted in superior resistance to extinction to all three intertrial intervals. No other differences were reliable. Results support the notion that memories are cue dependent even at short intervals.

A retrieval cue is a stimulus that is presented when a to-be-remembered event occurs and is reinstated or re-presented at some later time when recall is to occur. Previous data (Jobe \& Mellgren, 1974; Jobe, Mellgren, Feinberg, Littlejohn, \& Rigby, 1977) have demonstrated that the presence or absence of retrieval cues for the memory of previous trials has differential effects on various partial reinforcement phenomena. That is, when adequate reinstatement of retrieval cues occurs, N-length, small-magnitude-of-reward partial reinforcement, and single-alteration patterning effects occur. When nonreinstatement of retrieval cues occurs, however, none of the above effects occurs, although the partial reinforcement effect is obtained with large reward.

These studies have been directed toward resolving several apparent discrepancies in the spaced-trials literature, and they have been interpreted as supporting Capaldi's $(1967,1971)$ sequential hypothesis. Specifically, it is postulated that resistance to extinction is determined by the conditioning of the memory of nonreward to the instrumental running response on a subsequent rewarded trial $\left(\mathrm{S}^{\mathrm{N}} \cdot \mathrm{R}_{\mathrm{I}}\right.$ association). The previous work in our laboratory (Jobe \& Mellgren, 1974; Jobe et al., 1977) indicates that in order for the memory of nonreward to be conditioned, it must be reinstated on subsequent trials by adequate retrieval cues (i.e., startbox brightness the same as goalbox brightness).

These studies all involved retrieval cue manipulations with a long intertrial interval (ITI) (30 min to $24 \mathrm{~h}$ ). The purpose of the present experiment was to determine if the reinstatement of retrieval cues is less important at short ITIs than at long ITIs.

Jared B. Jobe is now at the U.S. Army Research Institute of Environmental Medicine, Natick, Massachusetts 01760. Mary Z. Mays is now at the Academy of Health Sciences, Fort Sam Houston, Texas. The authors would like to express their appreciation to Jack S. Leon for his aid in running subjects.

\section{METHOD}

\section{Subjects}

The subjects were 48 experimentally naive male albino rats, approximately 100 days old, of the Sprague-Dawley strain. The rats were purchased from the Holtzman Company, Madison, Wisconsin, and they were housed one per cage.

\section{Apparatus}

The apparatus consisted of a wooden straight-alley runway with start and run sections painted flat gray and two interchangeable goalboxes, one painted flat gray and the other, black and white vertical stripes. The apparatus was identical to that used by Jobe et al. (1977, Experiment 2). Results are reported as $1 /$ total time.

\section{Procedure}

Ten days prior to the experiment, the rats were placed on a 12-g/day food-deprivation schedule with free access to water. Following taming and pretraining, they received 6 trials/day at $50 \%$ partial reinforcement for a total of 96 trials. All rats received multiple $\mathrm{N}$-lengths of one, two, and three. The schedules used were NRNNRR, RRNNNR, NNRRNR, and RNNNRR, and each schedule was repeated four times. Five days of extinction at 6 trials/day followed acquisition.

The experimental design was a 2 (reinstatement condition) by 3 (ITI) factorial design. The reinstatement manipulation consisted of one-half of the rats receiving the gray goalbox on all trials (reinstatement condition) and the other half receiving the black-and-white striped goalbox (nonreinstatement condition). The ITIs used were $15 \mathrm{sec}, 15 \mathrm{~min}$, and $30 \mathrm{~min}$. Thus, the six groups were reinstatement $15 \mathrm{sec}$, nonreinstatement $15 \mathrm{sec}$, reinstatement $15 \mathrm{~min}$, nonreinstatement $15 \mathrm{~min}$, reinstatement $30 \mathrm{~min}$, and nonreinstatement $30 \mathrm{~min}$.

\section{RESULTS}

Extinction rates (Anderson, 1963) were analyzed by a 2 (reinstatement condition) by 3 (ITI) by 6 (days) analysis of variance. As can be seen in Figure 1, the reinstatement groups were reliably superior to the nonreinstatement groups, an observation supported by a significant main effect of reinstatement $[F(1,38)=8.44$, $\mathrm{p}<.01]$ and a significant Reinstatement by Days 

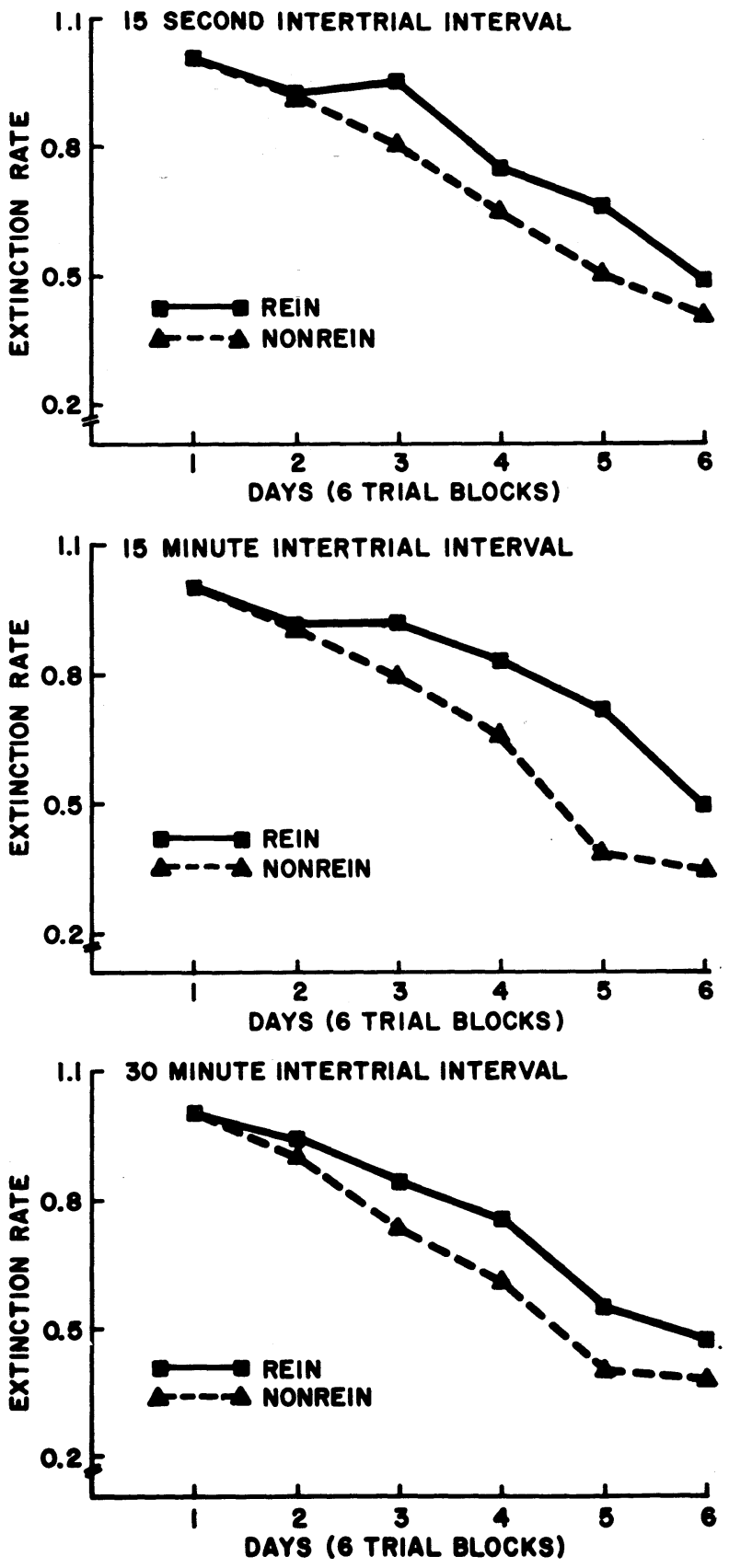

Figure 1. Extinction rates for the reinstatement and nonreinstatement groups at the $15-\mathrm{sec}$ ITI, 15-min ITI, and 30-min ITI for the terminal acquisition point and 5 days of extinction in six-trial blocks.

interaction $[F(5,190)=3.29, p<.01]$. The main effect of days was also significant, as would be expected $[F(5,190)=104.58, p<.001]$. ITI did not result in any significant main effect or interaction (all $\mathrm{Fs}<1$ ).

\section{DISCUSSION}

Consistent with earlier studies using long ITIs of $30 \mathrm{~min}$ to $24 \mathrm{~h}$ (Jobe \& Mellgren, 1974; Jobe et al., 1977), the failure to adequately reinstate $\mathrm{S}^{\mathrm{N}}$ significantly attenuated resistance to extinction at ITIs of $15 \mathrm{sec}, 15 \mathrm{~min}$, and $30 \mathrm{~min}$. Specifically, reinstatement of retrieval cues (using a goalbox of the same brightness as the startbox) resulted in superior resistance to extinction compared with nonreinstatement of retrieval cues (using a goalbox of different brightness from the startbox). ITI was not a significant variable, at least within the values used in the present experiment.

It might be argued that the results of the present experiment are due to a confounding of similarity of the start- and goalboxes or to a confounding of the presence of a blackand-white striped goalbox during acquisition and extinction. However, the data of Jobe et al. (1977, Experiment 3) indicate that this is not the case.

These results are not in agreement with the hypothesis that the memory of the previous goal event would carry over at a 15-sec ITI (short-term memory) and reinstatement would not be necessary. These results do, however, support the notion that the memory retrieval process at short ITIs is similar to that at long ITIs and that memory is cue dependent (Capaldi, 1971). That is, the memory of a goal event returns when the external stimuli that initiated the memory are once again presented, even at intervals as short as $15 \mathrm{sec}$. If a different stimulus situation is presented, the memory is not fully reinstated, again even at intervals of $15 \mathrm{sec}$. Together with previous studies (Jobe \& Mellgren, 1974; Jobe et al., 1977), the results demonstrate that the reinstatement-nonreinstatement manipulation is the crucial variable in determining whether or not partial reinforcement and sequential effects occur, and not the ITI, as hypothesized by other theorists (e.g., Amsel, 1967; Gonzalez \& Bitterman, 1969).

\section{REFERENCES}

Amsel, A. Partial reinforcement effects on vigor and persistence. In K. W. Spence \& J. T. Spence (Eds.), The psychology of learning and motivation (Vol. 1). New York: Academic Press, 1967.

Anderson, N. H. Comparisons of different populations: Resistance to extinction and transfer. Psychological Review, 1963, 70, 162-179.

Capaldi, E. J. A sequential hypothesis of instrumental learning. In K. W. Spence \& J. T. Spence (Eds.), The psychology of learning and motivation (Vol. 1). New York: Academic Press, 1967.

CAPAldi, E. J. Memory and learning: A sequential viewpoint. In W. K. Honig \& P. H. R. James (Eds.), Animal memory. New York: Academic Press, 1971.

Gonzalez, R. C., \& Bitterman, M. E. Spaced-trials partial reinforcement effect as a function of contrast. Journal of Comparative and Physiological Psychology, 1969, 67, 94-103.

Jobe, J. B., \& Mellaren, R. L. Successive nonreinforcements (N-length) and resistance to extinction at spaced trials. Journal of Experimental Psychology, 1974, 103, 652-657.

Jobe, J. B., Mellgren, R. L., Feinberg, R. A., Littlejohn, R. L., \& RigBY, R. L. Patterning, partial reinforcement, and $\mathrm{N}$-length effects at spaced trials as a function of reinstatement of retrieval cues. Learning and Motivation, 1977, 8, 77-97.

(Received for publication January 11, 1982.) 